\section{Alles über die Haut mit einem Griff}

D odo odopompholyx - was ist das noch einmal? Akne - welche klinischen Formen gibt es? Psoriasis vulgaris welche Therapieoptionen bestehen? Antimykotische Salbe - wie wird die korrekt rezeptiert? Ob es um Dermatologie, Allergologie oder Umweltmedizin geht: Ein einziger Griff genügt, um zur gesuchten Information zu gelangen. Der neue „Altmeyer, Paech“ bietet in bewährter Form präzise und gut strukturiert alles Wissenswerte zu Klinik, Diagnostik und Therapie.

In der zweiten Auflage wurden die Inhalte wie auch die Abbildungen um- fassend aktualisiert. Über 5.000 Stichwörter auf 2.100 Seiten behandeln alle Facetten der Dermatologie, Allergologie und Umweltmedizin. Wo erforderlich, visualisieren Tabellen kompakte Informationen und machen sie transparenter. Anschaulich und instruktiv illustriert werden die Inhalte durch 1.476 ausgewählte Abbildungen. Außerdem findet der Leser im aktualisierten Rezepturverzeichnis über 298 Magistralrezepturen auf dem aktuellen Stand der pharmazeutisch-technologischen Wissenschaft. Ganz neu dazugekommen ist ein separates Synonymenverzeichnis,

\title{
Vor Fehlern ist niemand gefeit
}

D er Herausgeber ist selbst Chirurg und blickt auf eine langjährige klinische und Gutachtertätigkeit zurück. Pro Jahr kommen in Deutschland heute rund 40.000 Behandlungsfehlervorwürfe zur Anzeige, von denen allerdings nur ein geringer Teil wirklich zur Verurteilung führt. Imhof geht in den einzelnen Kapiteln dezidiert darauf ein, was heute als Behandlungsfehler gilt. Etwa die Hälfte des Buches erläutert, wo und wie es zu Behandlungsfehlern kommt. Schließlich wird auch der mühsame Weg durch die Instanzen geschildert, wobei der Autor klar Stellung bezieht, wie die Versicherungsträger auch bei eindeutigem Fehlernachweis Schadensersatzzahlungen teilweise über Jahre verzögern und damit die Betroffenen zermürben. Aber auch die „Prozessfreudigkeit“ der Patienten wird sachlich thematisiert. Im letzten Kapitel geht Imhof dann unter anderem darauf ein, dass wir als Ärzte mit Fehlern ehrlich umgehen sollten, und untermauert dies mit einer Bemerkung, die einem berühmten Standesvertreter des 19. Jahrhunderts, Theodor Billroth, zugeschrieben wird: „Nur armselige, eitle Toren und Schwäch- das gebräuchliche und historische $\mathrm{Be}$ griffe wie Anglizismen gleichermaßen berücksichtigt und einen bequemen und sicheren Weg durch das dermatologische Sprachgewirr weist.

red

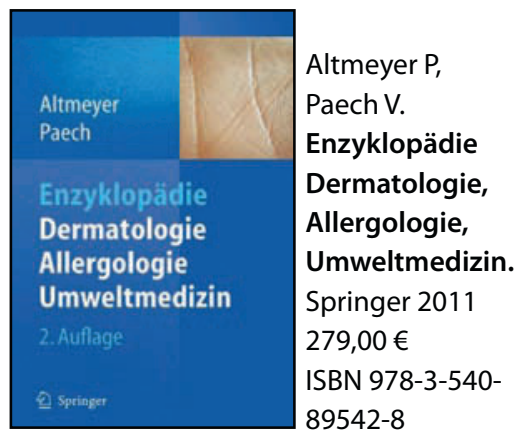

linge scheuen sich, begangene Fehler einzugestehen."

Insgesamt ein flüssig zu lesendes Buch, das medizinische, rechtliche und ethische Aspekte eines Problems beleuchtet, das jeden von uns treffen kann. red

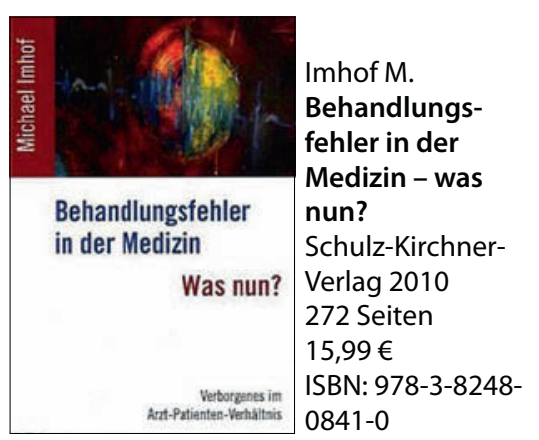

besser einschätzen kann, trägt wesentlich dazu bei, eine Gesprächssituation positiv zu beeinflussen und wird in Konfliktsituationen eine Reihe von Lösungswegen kennen und anwenden können. red

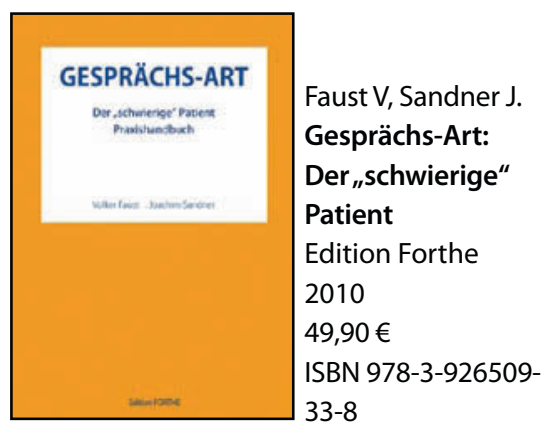

Seele hat Konjunktur. Kommunikation mit Patienten ist daher das wichtigste Instrument in einer Praxis oder Klinik. Das Buch Gesprächs-Art kann Ärzte ebenso wie ihr Team dabei unterstützen. Die Autoren, Joachim Sandner und Volker Faust, vermitteln die Grundlagen guter Kommunikation speziell ausgerichtet auf den Patientenkontakt und stellen relevante Störungsbilder aus dem seelischen und psychosozialen Bereich umfassend dar. Wer sich mit diesen Grundlagen vertraut macht und dabei sein Gegenüber mangelnde Achtsamkeit und schlechtes Zeitmanagement. Aber auch die kranke 